\title{
A ciência e a filosofia moderna em uma perspectiva leibniziana
}

\section{Modern Science and philosophy according to Leibniz}

DOI: https://doi.org/10.20873/rpv6n1-89

\section{Patrícia Coradim Sita}

Orcid: https://orcid.org/0000-0002-7751-6879

E-mail:pcsita@uem.br

\section{Resumo}

Nesse artigo apresentamos algumas características do surgimento da ciência moderna para, na sequência, analisar o modo segundo o qual Leibniz lida com a proposta de um novo tratamento intelectual da natureza.

\section{Palavras-chave}

Física. Metafísica. Forças primitivas. Forças derivadas. Filosofia moderna.

\begin{abstract} Leibniz deals with the proposal of a new intellectual treatment of nature.

\section{Keywords}

Physics. Metaphysics. Primitive forces. Derivative forces. modern philosophy.
\end{abstract}

In this article we present some characteristics of the emergence of modern science. Then, we analyze the way

\section{Introdução: elementos históricos}

Um dos grandes marcos da ciência moderna é a chamada revolução científica. A transformação promovida pela revolução científica na forma de se lidar com o conhecimento e com o entendimento durante a modernidade é bem conhecida e continua sendo muito estudada atualmente. Entretanto, quando falamos de revolução científica na modernidade ainda é preciso que se destaque que a ciência do título 'revolução científica' não é a ciência tal como nós a compreendemos e praticamos hoje. 
Paulo Rossi, historiador da ciência, apresenta algumas características dessa revolução. Entre elas ele lista a chamada matematização da natureza, a superação das teorias do movimento aristotélicas, o mecanicismo e outras mudanças ocorridas no entendimento destes indivíduos e no modo como eles se relacionavam com o outro e com a natureza a fim de compreender e alcançar a verdade. Segundo Rossi (1992), o mecanicismo, a medicina, a física, a astronomia e a matemática eram áreas nas quais havia uma intensa atividade. 0 historiador lembra o papel fundamental de Bacon para o estabelecimento do ingresso da humanidade na chamada ciência moderna. Para Rossi Bacon assumiu uma importante perspectiva que viria a marcar aquilo que atualmente nós entendemos como ciência: a perspectiva das sociedades, a perspectiva das discussões públicas, a perspectiva do fomento de ideias, da coletividade do saber. Rossi situa Bacon como um dos precursores da ciência moderna (ROSSI, 2006). 0 resultado da proposta baconiana pode ser visto, por exemplo, no surgimento da sociedade real inglesa das ciências em 1660, depois no surgimento da academia real de ciências da França em 1666. Essas sociedades ou academias tinham justamente o papel de reunir indivíduos dispostos a investigar a natureza em torno de um único modelo. Nesse sentido podemos dizer que nossos modernos promoveram um único modelo, mas não podemos dizer que a ciência empreendida naquela época compartilhava os esforços individuais em um trabalho coletivo.

Ao reivindicar destaque para a matemática no edifício do saber o mecanicismo promoveu um importante ajuste entre método e ontologia. Em virtude de seu papel central nesse programa da nova "filosofia natural" do séc. XVII a matemática passou a desempenhar a função de elo entre a ciência e a metafísica. Galileu e Descartes são grandes nomes desse período. 0 primeiro, por aplicar exemplarmente a matemática ao estudo dos movimentos naturais e reivindicar para si o título de 'filósofo', com base na convicção de que essa tarefa não se distingue daquela a que se dedicaram Aristóteles e seus seguidores medievais, ao procederem à investigação das causas, sobretudo das causas finais (VARGAS, 1996). O segundo, Descartes, por promover a mathesis universalis à condição de ciência geral que explica tudo quanto se pode procurar na natureza referente à ordem e à medida, sem aplicá-la a uma matéria especial. A mathesis universalis deveria proporcionar um único princípio último e, assim, exigir a aplicação 
de instrumentos matemáticos a objetos e propriedades que, até então, não eram encarados como dotados de qualquer afinidade ou identidade com o universo matemático (PATY, 1998).

Incluir passagem dos princípios em que afirma que os corpos devem ser tratados mecanicamente

Mas não creio que possamos esquecer de outros fatores como, por exemplo, do impacto que as grandes navegações tiveram sobre a filosofia naquele momento. Havia uma circunstância fechada, o filósofo estava tentando encontrar, de maneira universal, uma resposta para a questão sobre o próprio homem, um entendimento sobre a sua natureza, seja ela dependente ou independente de uma causa inteligente. E então nos deparamos com um novo mundo, cheio de pessoas que viviam em condições absolutamente distintas daquelas da Europa. 0 que fazer com a universalidade, nesse caso? Como lidar com isso, e com as diferenças evidenciadas? As navegações constituem-se como um fator que podemos elencar como tendo contribuído para o ressurgimento do ceticismo, ou para o surgimento de um novo ceticismo, e que acaba trazendo uma nova perspectiva da modernidade ${ }^{1}$. É interessante refletirmos sobre a defesa ou sobre a procura por uma natureza humana universal frente à novas naturezas humanas recém-descobertas, tão distintas das europeias. E o ceticismo incide justamente sobre a possibilidade de uma natureza única, universal, homogênea - que se torna insustentável mediante a descoberta de sociedades tão diversas como aquelas encontradas no novo mundo. A questão é que todo o movimento da modernidade pode ser visto como o resultado das várias mudanças ocorridas a partir, inclusive, das grandes navegações e sua descoberta do novo mundo, desde 1492. Mas as grandes navegações impactaram notadamente o século XVI, e Leibniz, como outros filósofos do séc. XVII, não está para o problema como Montaigne estava, por exemplo, mas o impacto dessas discussões afeta, certamente, aos filósofos do século XVII, através das diversas tentativas de responder ao ceticismo que havia ressurgido, muito em função dessas descobertas na perspectiva da natureza humana e na delimitação das suas fronteiras.

\footnotetext{
${ }^{1}$ Sobre o impacto das descobertas relativas às grandes navegações e o ceticismo na modernidade, veja-se Marcondes (2012).
} 
Segundo Olaso (1982), no final da década de 1670 Leibniz produz uma série de escritos destinados a refutar o ceticismo. Naquele momento, as investigações sobre o conhecimento se dedicam, antes de tudo, a responder aos argumentos céticos, organizando suas teses a fim de, ao menos, se proteger contra uma tradição filosófica ressurgida com força e que inviabilizava quaisquer pretensões racionais ao conhecimento verdadeiro ou definitivo. A discussão sobre os limites do que se pode saber é antiga na filosofia. Desde sua formulação radical, negando ao homem qualquer possibilidade de conhecimento, com Pirro de Elis (360-270 a.C.), passando por Montaigne (1533-1592) durante o renascimento, até o chamado 'ceticismo moderado' de alguns modernos, como Gassendi, o cético vem se dedicando à crítica da justificação racional do conhecimento, ao problema da decidibilidade, isto é, à dificuldade de se encontrar critérios de decisão quando nos deparamos com teorias concorrentes na explicação do mundo (cf. POPKIN, 2000).

A preocupação leibniziana, comum com a de outros filósofos modernos, era a de encontrar elementos que garantissem a validade do conhecimento de base racional.

Leibniz trabalha com o novo conceito de física, representativo da ciência moderna naquele momento, ou, mais precisamente, o modelo de ciência no século XVII. Mas as suas contribuições com as discussões sobre a natureza dos corpos e as relações entre eles passa pela recusa da explicação dualista de Descartes e pela defesa de uma reformulação da física a partir de uma perspectiva metafísica. A ciência leibniziana promove a passagem da mecânica para a dinâmica através dos conceitos de força e mônada, ou seja, traz os princípios metafísicos para o centro da física e das investigações sobre os corpos e suas naturezas.

\section{A nova física}

Refletindo especificamente sobre a ciência moderna, a ideia de ciência comum no século XVII era mais a de conhecimento do que o que atualmente empregamos sob a essa ideia e estava diretamente ligada à certeza, à ideia de uma verdade definitiva. Parece-me ser essa, ainda atualmente, a imagem de ciência que o senso comum cultiva. No centro das ambições científicas de 
Leibniz está um projeto - a scientia generalis - que também parece muito diferente do que nós chamaríamos hoje de "ciência".

De maneira semelhante, a física (pretendida aqui principalmente como o estudo do movimento dos corpos sob a ação de forças) e metafísica assumiam papeis específicos naquele momento. A física e a metafísica eram duas partes distintas do conhecimento teórico aristotélico, mas a forma como foram distinguidas por Aristóteles e seus seguidores não é a maneira pela qual nós agora os veríamos como duas empresas distintas - principalmente porque a física moderna não é mais o que Aristóteles chamou de "física".

Através do aperfeiçoamento da matemática e das abordagens que a química e a anatomia abriram para a natureza das coisas, tornou-se claro que as explicações mecânicas razões da figura e do movimento dos corpos, por assim dizer - podem ser aplicadas para a maioria das coisas a que os antigos referiam como resultado apenas do Criador ou a algum tipo de formas incorpóreas. Mas Leibniz (1989, p. 109-10) ainda tinha dúvidas:

Então, depois que sua tentativa teve pouco sucesso, embora antes de chegarem a fundamentos e princípios, eles proclamaram, como se alegrando prematuramente com sua segurança, que eles não poderiam encontrar nem Deus nem a imortalidade da alma por razão alguma... Pareceu-me indigno que nossa mente fosse cegada neste assunto por sua própria luz, isto é, pela filosofia. Comecei, portanto, eu mesmo a empreender um investigação ... Deixando de lado todos os preconceitos e suspendendo o crédito da Escritura e da história, [...] queria ver se a aparência sensorial dos corpos pode ser explicada sem se assumir uma causa incorpórea. No início, admiti prontamente que devemos concordar com aqueles contemporâneos filósofos que reviveram Demócrito e Epicuro e a quem Robert Boyle apropriadamente chama de filósofos corpusculares, como Galileu, Bacon, Gassendi, Descartes, Hobbes, e Digby, que ao explicar os fenômenos corporais, não devemos recorrer desnecessariamente a Deus ou a qualquer outra coisa, forma ou qualidade incorpórea ... até onde pode ser feito, tudo deve ser derivado da natureza do corpo e de suas qualidades primárias magnitude, figura e movimento. Mas e se eu demonstrasse que a origem das próprias qualidades primárias não pode ser encontrada na essência do corpo? Então, na verdade, esperaria que esses naturalistas admitissem que o corpo não é auto-suficiente e não pode subsistir sem um princípio incorpóreo (LEIBNIZ, 1989, p. 109-113).

Nessa passagem, com tantas informações interessantes, destacamos uma distinção nas possibilidades de explicação da natureza que aparece também em um outro pequeno texto (Antibarbarus physicus - Contra os bárbaros / 1706?): a explicação mecanicista e a metafísica. São dois níveis irredutíveis. Isso significa que a ciência e a metafísica operam em niveis 
separados, ou seja, as ciências naturais não podem conter aquilo que é próprio da metafísica. Nesse pequeno texto Lebniz se opõe a Newton, tanto quanto o faz nas correspondências com Clarke. As reflexões metafísicas de Leibniz o levam a uma situação bastante interessante. Por um lado, ele pode ser perfeitamente classificado como mecanicista, uma vez que afirma que, se podemos deduzir as causas naturais dos fenômenos como "os meteoros, os cometas e outros semelhantes" então perderíamos tempo querendo chegar a Deus através deles (cf. LEDUC, 2014). Por outro lado, a metafísica é parte fundamental e imprescindível das explicações.

No que diz respeito a concepção da relação entre a física e a metafísica Leibniz parece continuar comprometido com a posição apresentada em Confessio naturae de que princípios metafísicos não devem entrar em explicações físicas. Ainda que o autor não tenha conseguido decidir de forma satisfatória a questão do princípio incorpóreo dos corpos, ele apresenta em muitos textos a defesa da relação entre física e metafísica. Nesse sentido, a explicação mecânica dos fenômenos naturais não interfere na sua explicação metafísica. Para alcançar essa compreensão mais profunda do mundo físico o único caminho é a investigação dos seus fundamentos metafísicos, ou seja, é preciso apelar para os princípios metafísicos, que fornecem a base metafísica da ciência e, nesse sentido, as bases filosóficas do mecanicismo, o que supõe pensar que o objeto da física é metafísico. Para Leibniz, os modernos levaram a reforma muito longe, dentre outras razões, ao nivelarem as coisas naturais com as artificiais, não possuindo ideia suficientemente nobre da majestade da natureza.

Mas aquela passagem também nos oferece uma oportunidade de investigação de uma outra perspectiva leibniziana que queremos salientar. Trata-se da distinção entre "ciência" (tomada em um sentido moderno) e filosofia. 0 jovem Leibniz representa a metafísica e os filósofos mencionados representam a física mecânica quantitativa. São dados dois tipos de explicação. Por um lado, a nova ciência com base matemática, ou "filosofia da natureza", para a explicação dos fenômenos naturais. Por outro lado, ele afirma que a nova física mecânica não responde a questões mais fundamentais sobre princípios últimos da realidade. Um nível adicional de explicação é necessário para explicar adequadamente as características do mundo físico de que temos experiência. Segundo ele, nas noções físicas existem princípios implícitos 
que não podem ser reduzidos à extensão e ao movimento ${ }^{2}$. Deve haver nos corpos um princípio de unidade e atividade. As noções metafísicas expressam tal princípio mas, no entanto, essa explicação não deve entrar nas explicações adequadas da física, uma vez que a física propriamente dita se preocupa apenas com o tratamento matemático dos fenômenos que podem e devem ser explicados mecanicamente (cf. MURILLO, 2015).

Leibniz acredita que Galileo, Newton e Descartes estão tentando explicar os fenômenos naturais através de termos matemáticos e, nesse sentido, eles se recusam a se ocupar com as raizes metafísicas desses fenômenos (cf. DESCARTES, 1996, p. 64). Os corpos devem ser investigados e explicados apenas em função dos seus aspectos sensíveis e quantificáveis matematicamente. Esses filósofos, ao que parece, cada um ao seu modo, consideram inútil ou vão tentar buscar a essência, uma vez que não temos conhecimento possível sobre essa essência.

Outro ponto de destaque é que as verdades de fé poderiam ir contra as verdades que não estão fundadas senão nas leis da natureza prescritas por Deus, ou seja, contra as verdades que tem uma necessidade física ou moral e não metafísica. No momento em que a ciência moderna está se desenvolvendo, Leibniz pretende conciliar a razão e o progresso técnico-científico com a fé religiosa (Novos Ensaios, IV, 17). A forma para conseguir fazer isso é alterar ou ampliar a noção de razão. Ele não só admite a razão científica ou físico-matemática, mas também admite a razão metafísica e diz que ela pode ir além da ciência. A metafísica se salva facilmente do conflito entre fé e a razão científica (Carta a princesa-eleitora Sofia de 4 de novembro de 1696) (LEIBNIZ, 1989). A base natural de um conhecimento metafísico dispõe o homem naturalmente para a religião ou para a fé cristã.

Mas esse caminho adotado por Leibniz parece estar na contramão do movimento característico da modernidade que, em seu conjunto geral, visa fazer avançar as ciências naturais e destituir o modelo metafísico que prevalece durante a escolástica. A metafísica, nela mesma, precisa passar por uma reformulação. Nesse sentido a natureza não se mostra verdadeiramente

\footnotetext{
${ }^{2}$ A explicação mecanicista dos corpos como extensão não permite chegar a um princípio de realidade ou a verdadeira unidade dos fenômenos. Cf. Leibniz, Verdades primeiras (LEIBNIZ, 1982-2003, p. 397).
} 
em um nível sensível, mas no nível inteligível das ciências matemáticas. É isso o que Galileu quer dizer quando afirma que o livro da natureza está escrito em linguagem matemática ${ }^{3}$. Assim, se desconhecemos a linguagem dos números, das figuras, será impossível formar uma ideia exata dos fenômenos naturais. Descartes também identifica os produtos da natureza e da técnica $^{4}$. A nova ciência parece obscurecer o conceito tradicional de natureza como algo distinto da técnica. Diante do novo uso da matemática de Galileu e do mecanicismo de Descartes Leibniz propõem um novo sistema da natureza, uma reforma completa.

Os métodos da física matemática, entretanto, afastam-se da natureza real ou existente. Leibniz notou com muita clareza essa peculiaridade da nova física: ela consiste na distinção entre ciência e filosofia da natureza. Ele, ao invés de valorizar apenas as representações mecânicas observadas, opta por uma perspectiva filosófica na qual a natureza aparece como um mundo concreto subjacente e anterior ao das ciências e das técnicas. A natureza existente não é universal, uniforme, ela está integrada através de distintos indivíduos. Nesse sentido, o autor combate a tese daqueles que reduzem a riqueza do mundo corpóreo à objetividade científica. 0 conteúdo e o método da ciência remetem a um horizonte meta-científico, remetem a um fundamento lógico e metafísico do mundo. Para Leibniz é fundamental transcender as fronteiras da ciência para buscar os seus fundamentos. Assim, os fenômenos daquilo que está na superfície, daquilo que é provisório, pertencem a uma região interdisciplinar de princípios. Em cada porção de saber sobre o existente ele pretende a descoberta da unidade total e integradora. Leibniz admite a diversidade e a multiplicidade do mundo, ele admite a sua composição resultante de infinitos indivíduos autônomos. E nesse sentido surge a pergunta: como fazer para manter a unidade do mundo dentro dessa cosmovisão filosófica apesar dos resultados dispersos e parciais das ciências? Ele pretende elaborar um racionalismo metafísico que faça frente

\footnotetext{
${ }^{3} \mathrm{~A}$ famosa passagem de Galileu aparece em $O$ ensaiador (1623).

${ }^{4}$ Leibniz distingue as ciências puras das ciências aplicadas ou tecnologias. Apesar de distingui-las, ele admite que um conhecimento mais perfeito da natureza funda uma técnica mais adequada. Para ele, uma prática iluminada pela teoria supera uma prática cega ou sem teoria. Em todas as matérias capazes de razão, mesmo que se construam sobre os fundamentos da experiência, esse fundamento pode dar razão para tudo o que se faz e, nesse sentido, a teoria pode prevenir a prática quando você sabe meditar com ordem para não deixar escapar nenhuma circunstância que se deve ter em conta.
} 
ao racionalismo da física-matemática. E pretende preservar a unidade percebida no mundo, por isso o projeto moderno que valoriza a dispersão, a diversidade das bases e a especificidade das áreas do saber em conjuntos separados é estranha para Leibniz.

Segundo ele, existem princípios implícitos em corpos físicos que não podem ser reduzidos à extensão e movimento ${ }^{5}$. Deve haver nos corpos um princípio de unidade e atividade. As noções metafísicas expressam tal princípio e, no entanto, não devem entrar nas explicações da física, uma vez que a física propriamente dita se preocupa apenas com o tratamento matemático dos fenômenos que podem e devem ser explicados mecanicamente.

\section{A relação entre a física e a metafísica}

De fato, há desenvolvimentos muito importantes, e até transformadores, sobre a metafísica e a física desde a Confessio Naturae (1668-9) até os textos de 1678-9. Segundo Antognazza (2016), em um texto de 1676, De Arcanis Motus et Mechanica ad puram Geometriam reducenda (Os movimentos secretos), Leibniz introduziu o princípio fundamental da equivalência entre causa plena e efeito inteiro. Em janeiro de 1678, em artigo não publicado sobre as leis do movimento e na colisão de corpos (De corporum concursu), Leibniz focou na noção de força, quantificando-a pela primeira vez como o produto da massa $(\mathrm{m})$ pelo quadrado de velocidade $\left(\mathrm{v}^{2}\right)$. Em um Conspectus Libelli Elementorum Physicae, escrito entre o verão 1678 e o inverno 1678/79, ele notou que não é a quantidade de movimento (massa vezes velocidade ou mv) que é conservado no universo, como Descartes sustentou, mas a quantidade de força (massa vezes o quadrado da velocidade ou $\mathrm{mv}^{2}$ ), derrubando um dos princípios fundamentais da física cartesiana, ou seja, o princípio da conservação do movimento. Por último, mas não menos importante, em uma carta do outono de 1679 para seu novo patrono, o duque de Hanover, Johann Friedrich, Leibniz corajosamente endossou as formas substanciais no contexto de um relançamento de seu plano enciclopédico das Demonstrationes Catholicae (Demonstrationum Catholicarum Conspectus of 1668-9) (ANTOGNAZZA, 2016).

\footnotetext{
5 "E na verdade a noção de extensão não é primitiva, mas pode ser decomposta em seus elementos" (LEIBNIZ, 1982, p. 495).
} 
Devemos destacar que as formas substanciais nunca foram totalmente rejeitadas por Leibniz. Para ele, desde que sejam empregadas em um contexto metafísico apropriado, ao contrário de ser invocadas em explicações físicas de fenômenos naturais, elas constituem a melhor explicação. Este é um dos pontos-chave no Confessio Naturae.

Certamente deve-se notar que a filosofia dos corpos emergentes por volta de 1670-72 é diferente em pelo menos um aspecto crucial da filosofia dos corpos que sustentam o Confessio Naturae e outros textos de 1668-9. Nestes textos anteriores, no caso de seres não-racionais, Leibniz interpretou o "princípio incorpóreo" ou "princípio de atividade" necessário para corpos em termos de uma Mente transcendente (isto é, Deus) em vez de um princípio de ação imanente nos corpos. 0 afastamento dos perigos panteístas de tal visão em direção a uma metafísica totalmente comprometida com um princípio intrínseco de ação nos corpos é, sem dúvida, um momento importante. No entanto, essas mudanças nas visões metafísicas não implicam uma extensão da "forma substancial da teologia à física". No que diz respeito à concepção da relação entre física e metafísica, parece que Leibniz continua comprometido com a mesma posição expressa nas Confessio Naturae: princípios metafísicos - quer concebidos como formas substanciais ou como algum outro princípio incorpóreo - não devem entrar em explicações físicas de fenômenos naturais. Embora na época (Confessio Naturae) ele ainda não tivesse desenvolvido as ferramentas para pensar de forma satisfatória sobre o princípio incorpóreo exigido pelos corpos, ele já havia amadurecido uma visão sobre a relação entre a física e a metafísica que descobertas posteriores em ambos os campos não mudaram ${ }^{6}$. Em suma, o insight de Leibniz é duplo. (1) A matemática e a explicação mecânica dos fenômenos naturais é um empreendimento autônomo. Em tal explicação, não há lugar para formas substanciais. Em segundo lugar, (2) nossa compreensão dos corpos, ou, mais precisamente, nossa compreensão de sua natureza não se esgota com esse tipo de investigação. Muito pelo contrário. A fim de alcançar uma compreensão mais profunda do mundo físico é necessário alcançar seus fundamentos metafísicos e apelar para princípios metafísicos. Eles fornecem a base metafísica

\footnotetext{
${ }^{6}$ Cf. Correspondências com Clarke, 2ํ․ Escrito, §1. G, VII, 356.
} 
da física, as bases filosóficas do mecanismo, em oposição a ser o objeto da física propriamente dito ou a ser estendido à própria física.

E acompanho Antognazza quando ela diz que atribuir a gênese desta importante distinção a Leibniz não depende do delgado fio de um texto antigo isolado (2016, p. 27). Pelo contrário: uma longa série de passagens semelhantes, escrita ao longo do resto de sua vida, são bastante explícitos em fazer essa distinção, bem como em concordar com as perspectivas sobre o assunto já apresentadas na Confessio Naturae. No Discurso de Metafísica (1686), Leibniz destaca que as considerações de formas substanciais "não servem para nada no pormenor da física" e que "não se deve empregá-las na explicação dos fenômenos em particular". No entanto, "esta insuficiência e mau uso das formas não nos deve fazer rejeitar uma coisa cujo conhecimento é tão necessário em metafísica", embora "do mesmo modo pode um físico explicar as experiências servindo-se quer das experiências mais simples já realizadas quer das demonstrações geométricas e mecânicas, sem necessidade do recurso a considerações gerais, que pertencem a uma outra esfera" (§10). Leibniz (1946) diz ainda que subscreve

inteiramente a teoria corpuscular na explicação de fenômenos particulares; nesta esfera não tem valor para falar de formas ou qualidades. A natureza deve sempre ser explicada matematicamente e mecanicamente, desde que seja lembrado que os próprios princípios ou leis do mecanismo ou da força não depende apenas da extensão matemática, mas de certas razões metafísicas (carta para Arnauld, 14 de julho de 1668).

Por fim, deve-se ressaltar que, para Leibniz, as forças estudadas pela física não são forças primitivas, mas as forças derivadas baseadas nas primeiras. Forças primitivas (identificadas com formas substanciais ou primeiras enteléquias) são os objeto da metafísica, não da física. Já no primeiro momento, Leibniz apresenta qual é a subdivisão dos tipos de força que existem na natureza: as primitivas e as derivadas. Porém, mesmo que considere as forças derivadas uma limitação das primitivas, ele reconhece que estas não são suficientes para uma explicação inteligível dos fenômenos observados pelos sentidos (LEIBNIZ, 1982, p. 502). Assim, ele dá razão aos que discordam do uso das formas substanciais para a explicação dos fenômenos. Nesse sentido, Leibniz denuncia o uso indevido de formas substanciais na física aristotélica, embora 
as reivindique como princípios metafísicos de explicação necessária para fundamentar os fenômenos naturais e as forças físicas derivadas de que temos experiência.

Além disso, por meio da alma ou forma, há em nós uma verdadeira unidade que corresponde ao que denominamos "Eu"; isso não pode ter lugar nas máquinas artificiais ou em uma massa simples de matéria, por mais organizada que seja. Tais massas somente podem ser pensadas como semelhantes a uma multidão ou um bando, ou como a uma lagoa repleta de peixes, ou como a um relógio composto de molas e rodas. Porém, se não houvesse verdadeiras unidades substanciais nada haveria de substancial ou real em tal conjunto. Foi isso que forçou Gerauld de Cordemoy, a fim de encontrar a unidade verdadeira, a abandonar a doutrina de Descartes e adotar a de Demócrito acerca dos átomos. Mas os átomos da matéria são contrários à razão, além de serem compostos de partes, já que a insuperável união de uma parte a outra (mesmo se pudesse ser racionalmente compreendida ou imaginada) certamente não eliminaria a diferença entre elas. São somente os átomos de substâncias, quer dizer, as unidades reais absolutamente desprovidas de partes e que são as fontes das ações, os primeiros princípios absolutos da composição das coisas e, de certo modo, os últimos elementos na análise das substâncias. Elas podem ser denominadas pontos metafísicos; elas possuem alguma coisa da natureza da vida e um tipo de percepção, e os pontos matemáticos são seus pontos de vista para expressar o universo. Mas quando uma substância corpórea é contraída, todos os seus órgãos reunidos formam o que para nós é tão somente um ponto físico. Assim, a indivisibilidade dos pontos físicos é apenas aparente. Os pontos matemáticos realmente são indivisíveis, porém são apenas modalidades. Somente os pontos metafísicos ou substanciais (constituídos por formas ou almas) é que são tanto indivisíveis como reais e sem eles nada haveria de real, desde que sem unidades verdadeiras não haveria multiplicidade (LEIBNIZ, 2002, p. 11).

Leibniz ressalta a diferença entre quantidade ou força de movimento e força (vis viva). Se se afirma a diferença entre movimento e força deve-se também afirmar a constância da força, e não do movimento, que só sustenta sua conservação uma vez identificada à força. A capacidade de se manter constante não pertence à quantidade (ou força) de movimento cartesiana, mas é própria da força viva. 0 ponto em comum é que ambos concordam que tem que haver algo que se mantenha constante, que não se perca no movimento. Para Leibniz é fundamental a ideia de que algo deve se conservar sem exigir qualquer interferência, direta ou indiretamente.

Leibniz afirma que se existisse sempre a mesma quantidade de movimento seria possível alterar, nos corpos, as suas direções particulares ${ }^{7}$. Sua defesa da conservação da mesma quantidade de força no universo representa, fisicamente, a conservação metafísica do mesmo

\footnotetext{
${ }^{7}$ Sobre a distinção entre movimento e direção ver Esclarecimento do Sistema Novo da comunicação das substâncias, para servir de resposta ao que foi dito no Journal des Savants de 12 de setembro de 1695. Belo Horizonte: EdUFMG, 2002, § 20, p. 43.
} 
número de substâncias individuais. A inserção de um novo nessa estrutura significaria a desarmonia metafísica e, consequentemente, o desequilíbrio físico. Para Leibniz é preciso garantir a conservação da mesma quantidade de força no universo, em substituição à manutenção da quantidade do movimento ${ }^{8}$.

A crítica de Leibniz à Descartes e a substituição proposta pela noção de conservação da força (vis viva) assenta as bases da conservação da mesma quantidade de força no seu pressuposto dinâmico de mundo (novo em relação a Descartes) e na distinção entre tipos de força: as chamadas força viva e força morta. A força morta é a resistência ao movimento presente em todos os corpos (ele dá o exemplo da passagem do ponto para a linha para ilustrar a relação entre as forças). Forças mortas podem ser admitidas enquanto forças vivas quando deixam de ser potenciais para se tornarem movimentos efetivamente reais. Essa é a ideia fundamental da perspectiva crítica de Leibniz em relação à Descartes, e está baseada na pressuposição de que a força motriz de um corpo possui o caráter dinâmico (da motricidade) ao mesmo tempo em que possui o caráter metafísico (da força) (cf. LEIBNIZ, 1982, p. 508; PAPINEAU, 1981).

\section{0 projeto enciclopédico}

A aliança entre fé e razão e entre física e metafísica não são as únicas faces da proposta do autor para resolver as dificuldades trazidas pelas reflexões dos novos filósofos modernos. Leibniz ambiciona um projeto enciclopédico através do qual todo o conhecimento poderia ficar registrado, à disposição da humanidade para consultas e aprimoramentos. Nesse sentido, Leibniz, além de um método para ciência, é defensor de um modelo de conhecimento universalizado que, supostamente, superaria todas as dificuldades do empreendimento que, ao longo dos séculos, ocupa as investigações filosóficas. 0 projeto da enciclopédia está intimamente unido ao da ciência geral. Seu horizonte fica bastante bem delimitado quando notamos que a ciência, para o autor, contém os princípios de todas as demais ciências e também a maneira de usar esses princípios, de tal modo que qualquer um possa entender o mais difícil pelo mais fácil a

\footnotetext{
${ }^{8}$ Segundo a concepção moderna movimento e força são fenômenos distintos, diferentemente do que se notava na concepção aristotélica. Cf. KOYRÉ, 1991. Entretanto, para Leibniz, eles estão profundamente interligados.
} 
partir de uma reflexão acessível e de uma breve experiência, e qualquer um poderia falar as mais belas verdades e as práticas mais úteis quanto às possíveis aos homens a partir desses dados. Desse modo, os princípios primários da razão e da experiência estariam juntos com o método para que o conhecimento fosse possível.

Devemos notar, entretanto, que a ciência não é o mesmo que a enciclopédia. A partir da ciência geral se poderia reconstruir o estado atual dos saberes enciclopédicos e promover o seu desenvolvimento. Os projetos da enciclopédia e da ciência geral apontam para uma organização dos saberes em que se destaca a conexão mútua entre as partes apesar da multiplicidade da proposta e do próprio mundo. Unidade e conexão que são tão próprias do método e do conteúdo da ciência. Leibniz defende a pluralidade do conhecimento humano. Nesse sentido ele está aberto para a defesa de um conhecimento que não se restringe a áreas específicas do saber, mas que avança sobre todas as nuanças do entendimento da natureza. É a ideia da transdisciplinaridade, a ideia de que as questões relativas ao movimento dos corpos, por exemplo, não se esgotam com a investigação da física. Para compreender o movimento, é necessário que se compreenda elementos constituintes dos corpos, a relação desses elementos entre si e com outros elementos constituintes de outros corpos, o seu papel dentro de uma perspectiva ampla e plural. Nesse sentido, Leibniz parece defender uma ideia que é diferente daquela que vai caracterizar as revoluções científicas de cada uma das áreas do entendimento. Ele parece desejar, antes mesmo que a especificação ou que as especialidades se cristalizem, a superação dessas especificidades e oferecer um tratamento universal das entidades naturais do mundo.

O primeiro objetivo daquilo que se chama enciclopédia é a organização do corpo do conhecimento acumulado. 0 projeto enciclopédico visa eliminar a desordem e a falta de métodos das investigações científicas. A enciclopédia pode oferecer um quadro sistemático dos saberes já constituídos e, desse modo, servir como guia para as investigações futuras. Em algum sentido a proposta de Leibniz resgata o ideal de Bacon e se faz presente através das sociedades científicas do saber às quais Leibniz também se dedicará. Ele funda, em 1700, a Sociedade das Ciências de Berlim (Academia Real das Ciências da Prússia a partir de 1744). Essa sociedade, que deveria ser acompanhada de bibliotecas, museu de história natural, de artes e ofícios, de Jardim 
Botânico e zoológico, é pensada para apoiar o progresso das ciências e as suas aplicações técnicas ao comércio, por exemplo.

Nesse sentido, destacamos também que a proposta se configura como uma primeira tentativa para lançar uma rede de investigações científicas com base em indivíduos independentes que alimentam essa rede numa dedicação aos propósitos da ciência colocados acima dos interesses individuais. É a antecipação da colaboração própria do empreendimento científico tal como nós conhecemos. Mas esse é um projeto que se desenvolve às margens das universidades e, conforme o tempo passa, vai adquirindo contornos mais ambiciosos. De um depósito ou inventário dos saberes a enciclopédia passa a adquirir a áurea de uma unidade sistemática e a ser organizada de forma lógica demonstrativa e a desejar uma heurística ou conjunto de procedimentos que permitam a produção de novos conhecimentos. Daí a necessidade de um alfabeto, de uma língua filosófica universal.

Podemos definir a característica da seguinte maneira, de acordo com Moreira: trata-se de "uma linguagem por meio da qual se pode colocar à prova a exatidão dos nossos pensamentos e raciocínios", uma linguagem simbólica, artificial, capaz de expressar sem ambiguidades todos os pensamentos humanos e "destinada a proporcionar o registro e o acesso sensível àquela estrutura, com a finalidade de pôr a mostra a estrutura dos raciocínios e das relações entre eles" (2019, p. 197). Para Leibniz, a característica universal estava diretamente ligada ao projeto da enciclopédia, que reuniria todas as artes e ciências conhecidas pelo homem, em todos os setores do pensamento. A posse de um alfabeto dos pensamentos humanos nos ofereceria o idioma universal a partir do qual se poderia construir uma característica universal. Nesse sentido, o ato de pensar se equipararia ao de calcular. Discordando de Descartes, para quem a proposta de uma língua universal seria irrealizável por depender da verdadeira filosofia e porque é impossível enumerar todos os pensamentos dos homens ${ }^{9}$, Leibniz afirma:

Tal língua pode ser construída apesar da filosofia não ser perfeita; na medida em que a ciência humana crescer, crescerá também tal língua. Na espera, ela poderá constituir uma ajuda maravilhosa para utilizar aquilo que sabemos, para tomar consciência daquilo que nos falta e para descobrir os

\footnotetext{
${ }^{9}$ Rossi (1992, p. 346) questiona se essa posição leibniziana é constante. Segundo ele, a posição de Leibniz apresenta "não poucas incertezas".
} 
meios para alcançar tal objetivo, mas sobretudo poderá servir para eliminar, exterminando-as, as controvérsias nos assuntos que dependem da razão. Porque, então, calcular e raciocinar serão a mesma coisa (COUTURAT, p. 28).

Para Leibniz, a ideia de unidade e continuidade do saber é muito preciosa.

A imagem do oceano aparece expressando a continuidade de todo o conhecimento humano:

o corpo inteiro dos saberes pode ser considerado como o oceano, que é contínuo em todas as partes e sem interrupção ou partição, ainda que os homens concebam partes nele e lhes deem nomes segundo a sua comodidade. E do mesmo modo como há mares desconhecidos ou que não são navegados mais do que por viajantes que a sorte ou o azar lançou até lá, se pode dizer que há saberes os quais se tem conhecimento apenas por sorte ou sem intenção (COUTURAT, p. 530-531).

Isso não significa, entretanto, que a unidade e continuidade das ciências impedem a sua distinção. 0 uno e o múltiplo ocorrem simultaneamente no cosmo mas cabe às ciências particulares a investigação dos fenômenos. A construção da língua universal é o que poderá levar à realização da ars inveniendi (método científico ou da descoberta).

De minha parte, só estudava as Matemáticas porque encontrava nelas os vestígios da arte de inventar (arte da descoberta, método científico, método da descoberta) em geral; e acredito haver descoberto finalmente que nem sequer o Sr. Descartes havia chegado a penetrar nos mistérios dessa grande ciência (LEIBNIZ, 1989, p. 51).

A capacidade de inovar, de criar algo diferente a partir de uma base comum e simples que possa ser aplicável às outras áreas do conhecimento está na origem da ars inveniendi leibniziana, resultado do seu desejo por um método que permitisse efetivamente a ampliação do conhecimento, ou que permitisse o ordenamento racional dos novos conhecimentos, o que deveria possibilitar que outros fossem descobertos na sequência.

O sinal, que na língua universal é dado a um determinado objeto ou a uma determinada noção, não serve apenas para identificar as relações que ocorrem entre a coisa significada e as outras pertencentes à mesma classe; do mesmo modo, não serve apenas para indicar a posição ou o lugar que tal objeto ocupa no esquema do universo. Servirá, acima de tudo, para indicar as experiências que devem ser racionalmente empreendidas para ampliar o nosso conhecimento. 
Para Leibniz, o objetivo é descobrir um método capaz de se constituir enquanto chave da realidade, uma ciência verdadeiramente universal capaz de revelar a estrutura da realidade e seu ordenamento natural. Essa expectativa, que foi inaugurada com De arte combinatoria (1666) se mantém presente em vários trabalhos posteriores de Leibniz (DASCAL, 1978, p. 1314) e nos ajuda a compreender a perspectiva científica ampla do filósofo.

Do projeto inicial da característica universal o fruto mais exitoso foi o cálculo infinitesimal. Leibniz constrói a formulação do cálculo como meio de análise dos problemas tanto na própria matemática quanto na física, em especial quanto ao problema do movimento no domínio da nova física.

O problema das relações entre os signos e o pensamento estava no centro das reflexões clássicas sobre os signos e sobre a linguagem. Leibniz, porém, ao invés de se limitar a considerar os sinais apenas em sua função comunicativa, volta sua atenção para as funções cognitivas (cf. DASCAL, 1978, p. 222-224). Ele atribui aos signos um papel constitutivo de toda atividade mental superior, oferecendo uma nova forma de abordagem dos caracteres e signos e permitindo uma nova perspectiva de tratamento da matemática e da filosofia.

\section{Considerações finais}

Leibniz assume uma cosmologia a partir de um mecanismo teleologicamente orientado, diferentemente do mecanicismo cartesiano, por exemplo, que estava restrito ao funcionamento da matéria. Ele aceita a ocorrência de certo mecanismo presente nos corpos e passível de ser quantificado em termos matemáticos. Esse mecanismo, contudo, não pode ser visto como uma explicação completa relativamente aos corpos. Antes de qualquer coisa todo movimento e disposição das partes dos compostos devem-se ao ordenamento das forças primitivas constituintes de qualquer corpo. A diferença entre a concepção leibniziana e as concepções de Newton ou de Descartes sobre o espaço e a matéria não são de natureza metafísica, apenas, mas são fruto de uma opção metodológica.

Chamamos opção metodológica aos padrões que regulam o recurso às diversas ordens de razões (metafísicas, ontológicas, teológicas) na construção e na justificação das explicações 
científicas abrangentes da concepção de mundo físico desses autores, e que, no caso de Leibniz, são responsáveis por incorporar em suas explicações as recentes descobertas do cálculo infinitesimal, entre outras.

Concluindo, a ciência leibniziana não pode ser contida em rótulos e delimitações muito estreitas. As tradicionais classificações (empirista, racionalista, idealista) não são capazes de conter a diversidade e as ambições universalizantes de Leibniz. Essa característica, que por vezes serve de ilustração para a caricatura de um filósofo fora do seu tempo, não parece ter lugar quando se investiga sua obra. Muito mais do que "o filósofo responsável pelo cálculo infinitesimal", Leibniz apresenta uma mente atenta e genial que se ocupou das bases ontológicas e metodológicas do novo modelo de saber, cujas marcas são indeléveis. Como diz Juan Arana (2009), na apresentação do volume Escritos científicos de Leibniz, ele "ofereceu soluções válidas algumas vezes, formulou propostas interessantes em outras ocasiões; apresentou desafios estimulantes sempre".

\section{Referências bibliográficas}

ANTOGNAZZA, R. M. Philosophy and Science in Leibniz. In: STRICKLAND, L.; WECKEND, J.; E. VYNCKIER, (Eds), Tercentenary Essays on the Philosophy and Science of G. W. Leibniz. Palgrave Macmillan, 2016, pp. 19-46.

COUTURAT, L. La logique de Leibniz, d'après des documents inédits. Hildesheim: Olms, 1985.

DASCAL, M. La sémiologie de Leibniz. Paris: Aubier Montaigne, 1978.

DESCARTES, R. Les principles de la philosophie. Paris: Vrin, 1996. (Oeuvres de Descartes, publiées par Ch. Adam et P. Tannery, tome IX).

LEDUC, C. Leibniz Et Les Qualités Occultes. Studia Leibnitiana, v. 46, n. 2, 2014, p. 187-205.

LEIBNIZ, G. W. Die philosophischen Schriften von Gottfried Wilhelm Leibniz. Ed. C. I. Gerhardt (G), 7 vols. Berlin 1875-1890, VII, 2005.

LEIBNIZ, G. W. Correspondencia con Arnauld (1686-1690). Trad. V. Quintero. Buenos Aires: Editorial Losada, 1946.

LEIBNIZ, G. W. Discours de métaphhysique suivi de Monadologie. Édition établie, présentée et annotée par Michel Fichant. Paris: Gallimard, 2004.

LEIBNIZ, G. W. Filosofia para princesas. (Cartas) Trad. Javier Echeverría. Madrid: Alianza Editorial, 1989.

LEIBNIZ, G. W. Introducción. In: Leibniz, G. W. Escritos filosóficos. Ed. E. Olaso. Trad. T. E. Zwanck. Madrid, A. Machado, 1982. 
LEIBNIZ, G. W. Sistema novo da natureza e da comunicação das substâncias (1695). Trad. Edgar Marques. Belo Horizonte: EdUFMG, 2002.

LEIBNIZ, G. W. The Confession of Nature against Atheists. In: LEIBNIZ, G. W. Philosophical Papers and Letters. Translated and edited, with an introduction by Leroy Earl Loemker. 2. ed. Dordrecht: Kluwer Academic Publishers, 1989.

LEIBNIZ, G. W. Verdades primeiras. In: LEIBNIZ, G. W. Escritos filosóficos. Edición de Ezequiel de Olaso. Trad. Roberto Torreti, Tomás Zwanck e Ezequiel de Olaso. Madrid: A. Machado Libros, 1982-2003.

LEIBNIZ, G. W. Obras filosóficas y científicas. Ed. Juan Arana. Vol. 8. Granada: Escritos científicos; Comares, 2009.

MARCONDES, D. Montaigne, a descoberta do Novo Mundo e o ceticismo moderno. Kriterion, v. 126, n. 53, 2012, p. 421-433.

MOREIRA, V. Contínuo e contingência. Estrutura e alçada da lei de continuidade na lógica de Leibniz. Curitiba: Kotter Editorial, 2019.

MURILLO, I. El sentido de la ciencia en Leibniz. Hacia una teoría integral de la ciencia. Madrid, 2015.

PATY, M. Mathesis universalis e inteligibilidade em Descartes, Trad. M. Corrêa-Paty. Cadernos de História e Filosofia da Ciência, vol. 8, n. 1, 1998, 9-57.

POPKIN, R. A história do ceticismo de Erasmo a Espinosa. Trad. Danilo Marcondes de Souza Filho. Rio de Janeiro: Francisco Alves, 2000.

ROSSI, P. A ciência e a filosofia dos modernos. São Paulo, Unesp, 1992.

ROSSI, P. Francis Bacon. Da magia a ciência. Trad. A. Bernardini. Londrina: Eduel, 2006.

VARGAS, M. História da matematização da natureza. Estudos avançados, v. 10, n. 28, 1996, p. 249-276.

Recebido em: $17 / 11 / 2020$

Aprovado em: 27/2/2021

\section{Patrícia Coradim Sita}

Possui graduação em Filosofia pela Universidade Estadual Paulista Júlio de Mesquita Filho (1996), mestrado em Filosofia pela Universidade Estadual Paulista Júlio de Mesquita Filho (2000) e doutorado em Filosofia pela Universidade Federal de São Carlos (2010). Atualmente é professora da Universidade Estadual de Maringá. Tem experiência na área de Filosofia, com ênfase em História da Filosofia Moderna, atuando principalmente nos seguintes temas: epistemologia e teoria do conhecimento. 